\title{
Ketogenic diet and its impact on mental processes of working population
}

\author{
Gašper Grom \\ Maksimum, d. 0. 0., Parmova 5I, 1000 Ljubljana \\ grom@maxximum.si
}

\begin{abstract}
Introduction: Ketogenic diet has been evaluated for wide variety of conditions, although it was initially used for treatment of epilepsy. As alternative dietary pattern it can represent means of better quality of life, improved ability to work and can prevent against cognitive decline, different dementias and more serious forms of neurodegenerative diseases. Methods: This is a systematic review of available literature. Results: As energy substrates and as signaling agents, ketones are potentially usable in mitochondriopathies that come with aging and neurodegenerative diseases, or are a consequence of stroke, trauma. It has antioxidative, antiinflammatory and antiseizure properties, improves bioenergetics of the brain, neuronal plasticity and has epigenetic function. Discussion: Expansion of current nutritional knowledge might be a paradigmatic shift in understanding what is "healthy diet" in general or in terms of segments of population. Key words: ketogenic diet, low carbohydrate, cognitive function, neuroprotective effect
\end{abstract}

E ffects of nutrition can most acutely be seen in the working population, as it affects work efficiency and absenteeism; yet the human nutrition, the foundation for chronic noncommunicable diseases and neurodegenerative diseases (ND) as well, should remain an open discussion in general. Chronic noncommunicable diseases: cardiovascular diseases, cancer, diabetes, musculoskeletal diseases, chronic respiratory diseases and some mental disorders, are estimated to represent up to $80 \%$ of deaths worldwide (Nacionalni inštitut za javno zdravje, 2017).

The public health organizations' recommendations of the past 40 years hardly have any positive effects. High availability of hyperpalatable food, stim- 
ulating the same reward circuits in the brain as drugs do (Volkow et al., 2012) should be counterweighed with a diet, protective of general and neurological health.

Ketogenic diet (KD) has been used with refractory epilepsy in children (Erickson et al., 2017) since 1920's. Most energy in a KD comes from fat with moderate protein intake and minimal carbs intake - one of the strictest ratios being $90: 2: 8$ (Oliveira et al., 2017). Most common rule implies 20 to 50 grams of carbs daily (Noakes et al., 2017). This induces ketosis: the liver starts producing ketone bodies (KB) as a metabolite of fats, glucose levels settle down and its concentration normalizes; insulin levels decrease, plasma $\mathrm{pH}$ decreases slightly as well (Oliveira et al., 2017). KB become the predominant source of energy for central nervous system (Paoli et al., 2014), musculoskeletal system and the heart (Barbanti et al., 2017). KD surpasses the benefits of high carbohydrate diets (Chang et al., 2017), for example in cancer, diabetes, cardiovascular diseases (Bazzano et al., 2015), AD and multiple sclerosis (Erickson et al., 2017). It's efficient for weight loss (Yancy et al., 2010, Bueno et al., 2013), appetite regulation, glycaemic control (Volek et al., 2009), stabilisation of hyperinsulinemia, improving insulin sensitivity and normalizing blood lipid profiles (Chang et al., 2017, Noakes et al., 2017, Oliveira et al., 2017). KD has been studied as adjuvant therapy in brain neoplasms. In animal models, KD prolongs survival by antioxidant properties and by supressing the tumour growth factors genes (Scheck et al., 2012).

Genesis, transport and oxidation of beta hydroxybutyrate (BoHB), one of the most important endogenous $\mathrm{KB}$, are well understood, exact mechanisms however not (Maalouf et al., 2009, McCarty et al., 2015). As direct and indirect histone deacetylase inhibitor, BoHB has epigenetic function (Newman et al., 2014). BoHB also directly inhibits the $\mathrm{NLRP}_{3}$ protein, the main motor of inflammatory response in autoimmune and autoinflammatory diseases, diabetes type 2, AD and atherosclerosis (Youm et al., 2015).

In this paper we focus on $\mathrm{KD}$ as a means of protection for the nervous system and its potential within the realm of mental, cognitive and memory processes.

\section{Methods}

Primary literature for this narrative attempt at a systematic review search was Medline / Pubmed database. A string of keywords using MESH, [tiab] descriptor and Boole operators AND, OR and NOT with publication date criteria (2007 and on) and human studies were used. The search string: (ketogenic diet[mesh] OR (ketogenic [tiab] AND diet [tiab]) OR diet carbohydrate restricted [mesh] OR (carbohydrate [tiab] AND restricted [tiab]) OR ketone bodies [mesh] OR (ketone [tiab] AND bodies [tiab]) OR 3-hydroxybutyric acid [mesh] OR beta Hydroxybutyrate [tiab]) AND ((neuroprotection [mesh] OR neuroprotection [tiab] OR neuroprotective [tiab]) OR (cognition [mesh] OR cognition [tiab] OR 
cognitive function [tiab]) OR (memory [mesh] OR memory [tiab]) OR (memory disorders[mesh] OR (memory [tiab] AND disorders [tiab])) OR (Memory Disorders/diet therapy[Mesh])) NOT epilepsy [mesh]. Google Scholar search results, found by using the string »ketogenic diet, low carbohydrate, cognitive function, memory creation, neuroprotective «, were added to initial Pubmed search. Some results were excluded based on weak connection to the topic.

\section{Results}

Neuronal hypometabolism appears to be foundation in pathogenesis of many ND (Castellano et al., 2015): consequences of metabolic disorders set off in the preclinical stages of the disease. This is a common ground for new therapies for ND, especially in those where neuroprotection is the key (Stafstrom et al., 2012). Ketosis could be the opportunity to open paracrine and autocrine signalling mechanisms to influence cometabolism within the nervous system and tumours as a way to achieve therapeutic ends (Puchalska et al., 2017).

Mitochondria do not only supply cells with energy; they control the apoptosis, calcium levels and production and elimination of reactive oxygen species (ROS) (Milder et al., 2012). Nutrition based therapies are not only an option for rare mitochondriopathies but also for a spectrum of ND associated with aging (Procaccio et al., 2014). Mitochondrial dysfunction and the consequential hypometabolism of the nervous system that is a part of aging can be a source and a consequence of inflammatory processes (Currais, 2015).

$\mathrm{KD}$ is efficient with ameliorating symptoms of AD, Parkinson's disease and other ND (Hartman, 2012, Liśkiewicz et al., 2012, Mandla et al., 2013). $\mathrm{KD}$ can have a profound effect on neuronal plasticity, reduces inflammation, and improves bioenergetics in the brain ... (Procaccio et al., 2014). Mitochondrial function is impaired in ND - both systemically as well as in the brain (Wilkins et al., 2017). Nervous system's glucose dependency poses a risk to cognitive health (Farias et al., 2014). Neurons are adapted to using many different substrates for energy: glutamine, glutamate, lactate, pyruvate, KB. This is especially useful for people with regular hypoglycaemic episodes (Amaral, 2013), causing cognitive dysfunction, sensory disturbances and memory defects (Costantini et al., 20o8), verbal memory, digit symbol coding, digit span backwards, and map searching (Page et al., 2009).

Lack of energy due to hypometabolism and mitochondriopathies can be replaced by KB (Currais, 2015). Nutritional ketosis provides replenishment of the TCA cycle, restoration of neurotransmitter and ion channel function, and enhanced mitochondrial respiration. It helps cellular homeostasis by enabling signal pathways, developed as sensors of the energy state of the cell (Gano et al., 2014). These antiseizure, neuroprotective and antitumor properties of KD are not yet well understood (Maalouf et al., 2009, Thio, 2012).

Use of ketosis looks promising most prominently in AD (Grom, 2016). Decrease in glucose utilization has a very early onset with AD - much earli- 
er before pathologies and symptoms appear - and is much greater than in normal aging (Costantini et al., 2008). The changed metabolic environment reinforces the disease progression. Normalization of bioenergetics can be efficient in treatment neurological diseases (Masino et al., 2008, Zilberter et al., 2017).

$\mathrm{AD}$ is the most common type of dementia; it features accumulation of amyloid plaques and hyperphosphorylation of tau protein resulting in inflammatory response and oxidative stress. The mechanism is not well understood, but it seems that type 2 diabetes $\left(\mathrm{T}_{2} \mathrm{D}\right)$ accelerates these processes. Cerebral atrophy, hypometabolism of glucose and insulin resistance are featured in both diseases (Verdile et al., 2015). Cognitive decline is directly correlated to the level of glucose hypometabolism (de Leon et al., 1983). Some authors claim that AD is a type 3 diabetes (de la Monte et al., 2008).

In animal models of $\mathrm{AD}$, nutritional ketosis can ameliorate the extent of beta amyloid plaque accumulation (Krikorian et al., 2012). However, with patients without ApoE4 allele one of the nutritional options to improve mild cognitive impairments is adding medium chain triglycerides to the diet (Page et al., 2009, Farias et al., 2014, Sharma et al., 2014, Fernando et al., 2015, Hertz et al., 2015, Ohnuma et al., 2016).

Even in the excessive ROS model of AD, the KD is still useful as an antioxidative therapy. There is mixed evidence about the oxidative stress as the ground for $\mathrm{AD}$ in clinical trials, but it is possible that the antioxidant therapies did not succeed to deliver the antioxidants where they should be delivered (Rosini et al., 2014). KD might have been more successful.

$\mathrm{KB}$ help decrease the oxidative stress, while also being a substrate for energy. Both roles make KB highly neuroprotective agents (Cahill, 2006). KB mediate their antioxidative properties by activation of protective transcription factors (like Nrf2) that increase the production of antioxidants like glutathione and other enzymes (Milder et al., 2012).

In $\mathrm{KD}$, the metabolism of astrocytes producing purines (ATP and adenosine) is increased (Masino et al., 2008, Boison, 2013). In animal models there is increased autophagy of neurons in ketotic environment (McCarty et al., 2015).

Balancing excitotoxicity and cell death as a consequence can have a beneficial effect with patients who survived ischemic stroke and death of mitochondria that takes place sometime later after the event. In animal models these devastation to mitochondria can be alleviated by KB (Baxter et al., 2014). Postoperatively, KD could also be used with adult patients who suffered head trauma (Prins et al., 2014).

\section{Discussion}

Effects of KD are profound, but also complex. Yet applying any therapeutic means to affect the nervous system is rarely straightforward and simple to observe. 
Researching the neuroprotective properties of nutrition is by nature reductionist, regardless of the mechanism (epigenetic, direct or indirect modulation of individual physiological substances). Research is also mostly directed at improving known pathologies. To understand potential preventive effects some backwards deduction should be made.

\section{Conclusion}

Our insight into KD is barely scratching the surface. A lot of research both in humans and in animal models looks promising as expansion of our current nutritional knowledge and potentially as a paradigmatic shift in understanding what is "healthy diet" in general.

When the nervous system is in question, KD appears to have more efficient bioenergetics. We presented the research that deals with pathologies where the underlying hypometabolism is potentially the key to understand AD, Parkinson's disease, head trauma etc. Ketosis seems to be especially beneficial for mitochondria dysfunction. KB reduce the damaging effect of ROS, help body's own antioxidant capacity, while the ketone metabolism itself poses decreased oxidative stress to the tissues.

Neuroprotective effect of KD for now seems irrefutable, despite the lack of thorough understanding of the underlying mechanisms. Further research, especially in the form of clinical trials, is needed.

\section{References}

AMARAL, A.I. 2013. A ketone ester diet exhibits anxiolytic and cognition-sparing properties, and lessens amyloid and tau pathologies in a mouse model of Alzheimer's disease. Journal of Inherited Metabolic Disease, vol. 34, no. 6, pp. 1530-1539.

BARBANTI, P. et al. 2017. Ketogenic diet in migraine: rationale, findings and perspectives. Neurological sciences: official journal of the Italian Neurological Society and of the Italian Society of Clinical Neurophysiology, vol. 38, no. Suppl 1, pp. 111-115.

BAXTER, P., CHEN, Y., XU, Y. and SWANSON, R.A. 2014. Mitochondrial dysfunction induced by nuclear poly(ADP-ribose) polymerase-1: a treatable cause of cell death in stroke. Translational Stroke Research, vol. 5, no. 1, pp. 136-144.

BAZZANO, L. et al. 2015. Effects of low-carbohydrate and low-fat diets: a randomized trial. The The American Journal of Clinical Nutrition, vol. 102, no. 4, pp. $780-790$.

BOISON, D. 2013. Adenosine kinase: exploitation for therapeutic gain. Pharmacological Reviews, vol. 65, no. 3, pp. 906-943.

BUENO, N., VIEIRA DE MELO, I., LIMA DE OLIVEIRA, S. and DA ROCHA ATAIDE, T. 2013. Very-low-carbohydrate ketogenic diet v. low-fat diet for 
long-term weight loss: a meta-analysis of randomised controlled trials. The British Journal of Nutrition, vol. 110, no. 7, pp. 1178-1187.

CAHILL, G.F., Jr. 2006. Fuel metabolism in starvation. Annual Review of Nutrition, vol. 26, pp. 1-22.

CASTELLANO, C. et al. 2015. Lower brain 18F-fluorodeoxyglucose uptake but normal ${ }_{11 C}$-acetoacetate metabolism in mild Alzheimer's disease dementia. Journal of Alzheimer's Disease, vol. 43, no. 4, pp. 1343-1353.

CHANG, C.K., BORER, K. and LIN, P.J. 2017. Low-Carbohydrate-High-Fat Diet: Can it Help Exercise Performance? Journal of Human Kinetics, vol. 56, pp. 81-92.

COSTANTINI, L.C., BARR, L.J., VOGEL, J.L. and HENDERSON, S.T. 2008. Hypometabolism as a therapeutic target in Alzheimer's disease. BMC Neuroscience, vol. 9 Suppl 2, pp. S16.

CURRAIS, A. 2015. Ageing and inflammation - A central role for mitochondria in brain health and disease. Ageing Research Reviews, vol. 21, pp. 30-42.

DE LA MONTE, S.M. and WANDS, J.R. 2008. Alzheimer's Disease is Type 3 Diabetes-Evidence Reviewed. Journal of Diabetes Science and Technology, vol. 2, no. 6, pp. 1101-1113.

DE LEON, M.J. et al. 1983. Positron emission tomographic studies of aging and Alzheimer disease. AJNR. American Journal of Neuroradiology, vol. 4.

ERICKSON, N., BOSCHERI, A., LINKE, B. and HUEBNER, J. 2017. Systematic review: isocaloric ketogenic dietary regimes for cancer patients. Medical Oncology, vol. 34, no. 5, pp. 72.

FARIAS, G.A., GUZMÁN-MARTÍNEZ, L., DELGADO, C. and MACCIONI, R.B. 2014. Nutraceuticals: a novel concept in prevention and treatment of Alzheimer's disease and related disorders. Journal of Alzheimer's Disease, vol. 42, no. 2, pp. 357-367.

FERNANDO, W.M. et al. 2015. The role of dietary coconut for the prevention and treatment of Alzheimer's disease: potential mechanisms of action. The British Journal of Nutrition, vol. 114, no. 1, pp. 1-14.

GANO, L.B., PATEL, M. and RHO, J.M. 2014. Ketogenic diets, mitochondria, and neurological diseases. Journal of Lipid Research, vol. 55, no. 11, pp. 22112228.

GROM, G. 2016. Koristi ketogene diete za starejše: sindromi demence in Alzheimerjeva bolezen. Živeti življenje v varni starosti : zbornik predavanj, 2. Kongres gerontološke zdravstvene nege in oskrbe, Portorož, Strokovna sekcija medicinskih sester in zdravstvenih tehnikov v socialnih zavodih, Ljubljana.

HARTMAN, A.L. 2012. Neuroprotection in metabolism-based therapy. Epilepsy Research, vol. 100, no. 3, pp. 286-294.

HERTZ, L., CHEN, Y. and WAAGEPETERSEN, H.S. 2015. Effects of ketone bodies in Alzheimer's disease in relation to neural hypometabolism, be- 
ta-amyloid toxicity, and astrocyte function. Journal of Neurochemistry, vol. 134, no. 1, pp. 7-20.

KRIKORIAN, R. et al. 2012. Dietary ketosis enhances memory in mild cognitive impairment. Neurobiol Aging, vol. 33, no. 2, pp. 425 e419-427.

LIŚKIEWICZ, A., JĘDRZEJOWSKA-SZYPUŁKA, H. and LEWIN-KOWALIK, J. 2012. Characteristics of ketogenic diet and its therapeutic properties in central nervous system disorders. Annales Academiae Medicae Silesiensis.

MAALOUF, M., RHO, J.M. and MATTSON, M.P. 2009. The neuroprotective properties of calorie restriction, the ketogenic diet, and ketone bodies. Brain Research Reviews, vol. 59, no. 2, pp. 293-315.

MANDLA, U., SHARMA, P. and SHARMA, V. 2013. Dietary Factors in Alzheimer's Disease: A Compilation of Helping Evidences. International Journal of Research and Development in Pharmacy and Life Sciences, vol. 2, no. 5, pp. 545-552.

MASINO, S.A. and GEIGER, J.D. 2008. Are purines mediators of the anticonvulsant/neuroprotective effects of ketogenic diets? Trends in Neurosciences, vol. 31, no. 6, pp. 273-278.

MCCARTY, M.F., DINICOLANTONIO, J.J. and O'KEEFE, J.H. 2015. Ketosis may promote brain macroautophagy by activating Sirt1 and hypoxia-inducible factor-1. Medical Hypotheses, vol. 85, no. 5, pp. 631-639.

MILDER, J. and PATEL, M. 2012. Modulation of oxidative stress and mitochondrial function by the ketogenic diet. Epilepsy Research, vol. 100, no. 3, pp. 295-303.

NACIONALNI INŠTITUT ZA JAVNO ZDRAVJE. 2017. Bolezni [online]: Nacionalni inštitut za javno zdravje. Available at: http://www.nijz.si/sl/podrocja-dela/nenalezljive-bolezni-in-stanja/bolezni [Accessed 17.6. 2017].

NEWMAN, J.C. and VERDIN, E. 2014. Ketone bodies as signaling metabolites. Trends in Endocrinology and Metabolism, vol. 25, no. 1, pp. 42-52.

NOAKES, T.D. and WINDT, J. 2017. Evidence that supports the prescription of low-carbohydrate high-fat diets: a narrative review. British Journal of Sports Medicine, vol. 51, no. 2, pp. 133-139.

OHNUMA, T. et al. 2016. Benefits of use, and tolerance of, medium-chain triglyceride medical food in the management of Japanese patients with Alzheimer's disease: a prospective, open-label pilot study. Clinical Interventions in Aging, vol. 11, pp. 29-36.

OLIVEIRA, C.L. et al. 2017. A Nutritional Perspective of Ketogenic Diet in Cancer: A Narrative Review. Journal of the Academy of Nutrition and Dietetics.

PAGE, K.A. et al. 2009. Medium-chain fatty acids improve cognitive function in intensively treated type 1 diabetic patients and support in vitro synaptic transmission during acute hypoglycemia. Diabetes, vol. 58, no. 5, pp. 1237-1244. 
PAOLI, A., BIANCO, A., DAMIANI, E. and BOSCO, G. 2014. Ketogenic diet in neuromuscular and neurodegenerative diseases. BioMed Research International [electronic resource], vol. 2014, pp. 474296.

PRINS, M.L. and MATSUMOTO, J.H. 2014. The collective therapeutic potential of cerebral ketone metabolism in traumatic brain injury. Journal of Lipid Research, vol. 55, no. 12, pp. 2450-2457.

PROCACCIO, V. et al. 2014. Perspectives of drug-based neuroprotection targeting mitochondria. Revue Neurologique, vol. 170, no. 5, pp. 390-40o.

PUCHALSKA, P. and CRAWFORD, P.A. 2017. Multi-dimensional Roles of Ketone Bodies in Fuel Metabolism, Signaling, and Therapeutics. Cell Metabolism, vol. 25, no. 2, pp. 262-284.

ROSINI, M. et al. 2014. Oxidative stress in Alzheimer's disease: are we connecting the dots? Journal of Medicinal Chemistry, vol. 57, no. 7, pp. 2821-2831.

SCHECK, A.C., ABDELWAHAB, M.G., FENTON, K.E. and STAFFORD, P. 2012. The ketogenic diet for the treatment of glioma: insights from genetic profiling. Epilepsy Research, vol. 100, no. 3, pp. 327-337.

SHARMA, A., BEMIS, M. and DESILETS, A.R. 2014. Role of Medium Chain Triglycerides (Axona(R)) in the Treatment of Mild to Moderate Alzheimer's Disease. American Journal of Alzheimer's Disease and Other Dementias, vol. 29, no. 5, pp. 409-414.

STAFSTROM, C.E. and RHO, J.M. 2012. The ketogenic diet as a treatment paradigm for diverse neurological disorders. Frontiers in Pharmacology [electronic resource], vol. 3, pp. 59.

THIO, L.L. 2012. Neuroprotection in metabolism-based therapy. Epilepsy Research, vol. 100, no. 3, pp. 286-294.

VERDILE, G., FULLER, S.J. and MARTINS, R.N. 2015. The role of type 2 diabetes in neurodegeneration. Neurobiology of Disease, vol. 84, pp. 22-38.

VOLEK, J.S. et al. 2009. Carbohydrate restriction has a more favorable impact on the metabolic syndrome than a low fat diet. Lipids, vol. 44, no. 4, pp. 297-309.

VOLKOW, N.D. et al. 2012. Food and drug reward: overlapping circuits in human obesity and addiction. Current Topics in Behavioral Neurosciences, vol. 11, pp. 1-24.

WILKINS, H.M. and MORRIS, J.K. 2017. New Therapeutics to Modulate Mitochondrial Function in Neurodegenerative Disorders. Current Pharmaceutical Design, vol. 23, no. 5, pp. 731-752.

YANCY, W.J. et al. 2010. A randomized trial of a low-carbohydrate diet vs orlistat plus a low-fat diet for weight loss. A. Archives of Internal Medicine, vol. 170 , no. 2, pp. 136-145.

YOUM, Y.H. et al. 2015. The ketone metabolite beta-hydroxybutyrate blocks $\mathrm{NLRP}_{3}$ inflammasome-mediated inflammatory disease. Nature Medicine, vol. 21, no. 3, pp. 263-269. 
ZILBERTER, Y. and ZILBERTER, M. 2017. The vicious circle of hypometabolism in neurodegenerative diseases: Ways and mechanisms of metabolic correction. Journal of Neuroscience Research. 